\title{
Use of vision tests in clinical decision making about cataract surgery: results of a national survey
}

\author{
N A Frost, J M Sparrow
}

\begin{abstract}
Aim-To provide information on the use of vision tests in clinical decision making about cataract surgery in the UK.

Method-A questionnaire survey was mailed to 703 consultant ophthalmologists.

Results-A response rate of $70 \%$ was obtained. Monocular distance visual acuity was the only visual function that was tested routinely by all surgeons. Supplementary use of contrast sensitivity and glare testing was low. Many surgeons $(35 \%)$ were willing to consider surgery at acuity levels better than $6 / 9$ and a small but substantial number $(12 \%)$ indicated that they did not use an acuity criterion. Being prepared to consider surgery at relatively good levels of acuity was not associated with more common use of other tests of vision.

Conclusion-Many UK surgeons are prepared to consider cataract extraction at relatively good levels of visual acuity and use other vision tests infrequently.

(Br F Ophthalmol 2000;84:432-434)
\end{abstract}

Cataract surgery continues to make large demands on NHS resources. The role of vision tests and visual thresholds for cataract surgery has received recent attention because of the relation between the level of vision at which surgery is offered and the resulting volume of surgery that has to be provided. ${ }^{1-3}$ The available information ${ }^{4-7}$ shows that some surgeons in the UK are prepared to perform cataract extraction on patients with visual acuities as good as 6/6 Snellen, but it is uncertain whether a threshold based on visual acuity is actually included in surgical decision making. Nor is there information on which other vision tests (if any) is used to assist the decision making process.

\section{Method}

A questionnaire survey was mailed to consultant ophthalmologists practising in the UK in 1997 as part of an ongoing project to evaluate the population requirements for cataract surgery. The survey referred to elective cataract surgery in adults aged 55 years or older. Consultants were asked to give their answers based on their clinical judgment, ignoring the effects of waiting lists and funding arrangements. Thirty eight local consultant ophthalmologists who had already completed pilot versions of the questionnaire were excluded from the survey in advance.
The questionnaire asked about the use of vision tests when deciding whether to offer cataract surgery. Tests of distance acuity had been identified from the pilot study as those most often performed, and the consultants were asked to define a threshold level of acuity (if used) above which they would never offer cataract surgery.

\section{Results}

Of 703 questionnaires mailed, 489 replies were received, of which 473 respondents considered themselves eligible for inclusion in the study.

All respondents used distance acuity tests. In all, 449 of 470 (96\%) used near acuity tests, 51 of $459(11 \%)$ used contrast sensitivity, and 53 of $454(12 \%)$ used glare tests. The most frequently named tests of distance acuity were Snellen (334 surgeons) and logMAR (six surgeons). For near acuity testing the Faculty of Ophthalmologists' test types were most frequently named (86 surgeons) followed by Jaeger (22), Snellen (20), and vocational test types (14). Eighty six surgeons used contrast sensitivity and/or glare testing but the majority of surgeons (370) never used contrast sensitivity or glare tests. The most frequently named contrast sensitivity test was the Pelli-Robson chart (16 surgeons). For glare testing the most commonly named chart was the Snellen chart (16 surgeons). The most commonly named glare sources were sources of convenienceophthalmoscopes, pen torch, and anglepoise lamp (22 surgeons). The most frequently named purpose designed glare source was the BAT (seven surgeons). Other tests were mentioned infrequently. Potential vision tests such as interferometry, hyperacuity, use of the Maddox rod, and electrophysiological tests were mentioned by only four surgeons.

Table 1 provides a detailed description of the frequency of use of the more commonly used vision tests. Monocular distance acuity was the only test used routinely (in $81-100 \%$ of cases) by all surgeons. Although 449 surgeons stated that they used near acuity tests, a much smaller number (roughly one third) used these tests routinely. No surgeons routinely used contrast sensitivity tests. One surgeon routinely used glare testing.

Of 447 respondents, 155 (35\%) were willing to consider surgery at acuity levels better than $6 / 9$, and a small but substantial number of 55 $(12 \%)$ indicated that they did not use an acuity criterion. Table 2 illustrates the relation of acuity threshold to the use of (supplementary) vision tests other than distance acuity. Those who were likely to consider surgery at a better level of distance acuity were not more likely to use routinely other tests of vision. 
Table 1 The frequency of use of vision tests by eye

\begin{tabular}{|c|c|c|c|c|c|c|c|}
\hline \multirow[b]{2}{*}{ Vision test } & \multicolumn{7}{|c|}{ Frequency of use $e^{\star}$} \\
\hline & $\begin{array}{l}\text { Never } \\
0 \%\end{array}$ & $\begin{array}{l}1-20 \% \text { of } \\
\text { cases }\end{array}$ & $\begin{array}{l}21-40 \% \\
\text { of cases }\end{array}$ & $\begin{array}{l}41-60 \% \\
\text { of cases }\end{array}$ & $\begin{array}{l}61-80 \% \\
\text { of cases }\end{array}$ & $\begin{array}{l}81-100 \% \\
\text { of cases }\end{array}$ & $\begin{array}{l}\text { Missing } \\
\text { values }\end{array}$ \\
\hline Monocular distance acuity: op-eye $†$ & 0 & 0 & 0 & 0 & 0 & 472 & 1 \\
\hline Monocular distance acuity: fellow eye & 0 & 3 & 0 & 1 & 1 & 466 & 2 \\
\hline Binocular distance acuity & 90 & 123 & 37 & 40 & 18 & 98 & 67 \\
\hline Monocular near acuity: operated op-eye & 40 & 108 & 56 & 53 & 43 & 143 & 30 \\
\hline Monocular near acuity: fellow eye & 43 & 114 & 50 & 50 & 37 & 145 & 34 \\
\hline Binocular near acuity & 69 & 134 & 55 & 56 & 30 & 88 & 41 \\
\hline Monocular contrast sensitivity: operated op-eye & 421 & 45 & 1 & 0 & 2 & 0 & 4 \\
\hline Monocular contrast sensitivity: fellow eye & 425 & 38 & 0 & 0 & 1 & 0 & 9 \\
\hline Binocular contrast sensitivity & 425 & 18 & 0 & 0 & 0 & 0 & 30 \\
\hline Glare disability in the op-eye & 416 & 41 & 6 & 1 & 1 & 0 & 8 \\
\hline Glare disability in the fellow eye & 423 & 29 & 5 & 1 & 0 & 0 & 15 \\
\hline Binocular glare disability & 419 & 16 & 3 & 1 & 1 & 1 & 32 \\
\hline
\end{tabular}

${ }^{\star}$ Frequencies expressed as the percentage of cases where the test is used.

†Op-eye $=$ the eye being assessed for possible surgery.

\section{Discussion}

The response rate was comparable with the response rates obtained in similar studies in other countries. ${ }^{8-13}$ Comparison with these studies shows that UK surgeons appear to be the least frequent users of contrast sensitivity, glare, and potential vision tests.

In general, surgeons tended to use vision tests either routinely or rarely. This pattern of practice was also noted in a survey of Canadian surgeons. ${ }^{13}$ The present study did not inquire why particular tests were used with particular frequencies, but major criticisms of contrast sensitivity and glare tests in the study of Koch and $\mathrm{Liu}^{8}$ included lack of standardisation, lack of familiarity with the tests, lack of scientific validity, superfluity of the tests, cost, and lack of correlation with symptoms.

It has been suggested that contrast sensitivity and glare testing are likely to assume greater roles in the assessment of cataract patients with reasonably good Snellen acuities. ${ }^{14}$ This belief has been proposed as a possible explanation for international variations in preoperative testing. ${ }^{11}$ If this assumption is correct an increased frequency of use of supplementary tests would be expected among surgeons who consider surgery at relatively good levels of acuity, and among those who do not consider acuity as a

Table 2 Relation of acuity threshold to the use of vision tests other than distance acuity

\begin{tabular}{|c|c|c|c|}
\hline Number of surgeons & $\begin{array}{l}\text { Thresholds } \\
\text { worse than } 6 / 6\end{array}$ & $\begin{array}{l}\text { Thresholds } \\
6 / 6 \text { or better }\end{array}$ & $\begin{array}{l}\text { No acuity } \\
\text { criterion }\end{array}$ \\
\hline $\begin{array}{l}\text { Use any other test(s) routinely }(\mathrm{a}) \\
\text { Do not use other tests routinely }(\mathrm{b}) \\
\text { Percentage using other tests routinely }[100 \times \mathrm{a} /(\mathrm{a}+\mathrm{b})]\end{array}$ & $\begin{array}{l}96 \\
140 \\
41 \%\end{array}$ & $\begin{array}{l}50 \\
105 \\
32 \%\end{array}$ & $\begin{array}{l}22 \\
33 \\
40 \%\end{array}$ \\
\hline $\begin{array}{l}\text { Use any other test(s) routinely or occasionally } \\
\text { Do not use other tests } \\
\text { Percentage using other tests routinely or occasionally }\end{array}$ & $\begin{array}{l}227 \\
9 \\
96 \%\end{array}$ & $\begin{array}{l}149 \\
6 \\
96 \%\end{array}$ & $\begin{array}{l}51 \\
4 \\
93 \%\end{array}$ \\
\hline $\begin{array}{l}\text { Use near acuity tests routinely or occasionally } \\
\text { Do not use near acuity tests } \\
\text { Percentage using near acuity tests routinely or } \\
\text { occasionally }\end{array}$ & $\begin{array}{l}225 \\
10\end{array}$ & $\begin{array}{l}149 \\
6\end{array}$ & $\begin{array}{l}51 \\
3\end{array}$ \\
\hline $\begin{array}{l}\text { Use contrast sensitivity tests routinely or occasionally } \\
\text { Do not use contrast sensitivity tests } \\
\text { Percentage using contrast sensitivity tests routinely or } \\
\text { occasionally }\end{array}$ & $\begin{array}{l}24 \\
204\end{array}$ & $\begin{array}{l}16 \\
136 \\
11 \%\end{array}$ & $\begin{array}{l}7 \\
47 \\
13 \%\end{array}$ \\
\hline $\begin{array}{l}\text { Use glare tests routinely or occasionally } \\
\text { Do not use glare tests } \\
\text { Percentage using glare tests routinely or occasionally }\end{array}$ & $\begin{array}{l}29 \\
193 \\
13 \%\end{array}$ & $\begin{array}{l}14 \\
139 \\
9 \%\end{array}$ & $\begin{array}{l}5 \\
48 \\
9 \%\end{array}$ \\
\hline
\end{tabular}

The missing values can be calculated by subtracting the total numbers in each of the five groupings from 473 . criterion for surgery. The findings of the present study do not support this assumption.

The present study confirms earlier observations $^{4-7}$ that surgeons are prepared to consider surgery at relatively good levels of visual acuity. The present study has also revealed that some surgeons do not use an acuity criterion when considering whether to offer cataract extraction. Steinberg et al found visual acuity to correlate poorly with patients' preoperative satisfaction with their vision ${ }^{15}$ and to be a poor predictor of patient centred outcomes of cataract surgery. ${ }^{16}$ The surgical decision takes into account many other factors in addition to vision test results, but it is apparent that differences in the use and interpretation of vision tests may lead to differences in the numbers of cases that are eligible for surgery ${ }^{1-3}$ with important implications for the provision of cataract surgery services. The present uncertainty about the appropriateness and effectiveness of vision tests in contributing to the delivery of cost effective cataract surgery demands that further investigation is required to both clarify the role of vision testing and to explain the apparent international variations in clinical practice.

We thank the UK Department of Health, NHS Executive South and West, and the SAES study team; and all consultants who completed the questionnaire or assisted with the pilot study.

1 McCallum A. Assessment of the need for cataract extraction in the Northern Region. The second of two parts of the submission for the Diploma of Membership of the faculty of Public Health Medicine, 1991.

2 Wormald RPL, Evans JR. When does a lens opacity become a cataract? Estimating the effect of lowering the threshold a cataract? Estimating the effect of lowering the threshold for intervention on demand for services.

3 McCarty CA, Keeffe JE, Taylor HR. The need for cataract surgery: projections based on lens opacity, visual acuity, and personal concern. Br $\mathcal{F}$ Ophthalmol 1999;83:62-5.

4 Courtney P. The national cataract surgery survey: I. Method and descriptive features. Eye 1992;6:487-92.

5 Desai P. The national cataract surgery survey: III. Process features. Eye 1993;7:667-71.

6 Mordue A, Parkin DW, Baxter C, et al. Thresholds for treatment in cataract surgery. F Public Health Med 1994;16: 393-8.

7 Latham K, Misson G. Patterns of cataract referral in the West Midlands. Ophthalmic Physiol Opt 1997;17:300-6.

8 Koch DD, Liu JF. Survey of the clinical use of glare and contrast sensitivity testing. $\mathcal{F}$ Cataract Refract Surg 1990;16: 707-11.

9 Steinberg EP, Bass EB, Luthra R, et al. Variation in ophthalmic testing before cataract surgery. Arch Ophthalmol 1994; 112:896-902. 
10 Oshika T, Masuda K, Hayashi F, et al. Current trends in cataract and refractive surgery in Japan-1994 survey. Fap $\mathcal{F}$

11 Norregaard JC, Schein OD, Anderson GF, et al. International variation in ophthalmologic management of patients with cataracts: results from the International Cataract Surgery Outcomes Study. Arch Ophthalmol 1997;115 399-403.

12 Espallargues $\mathrm{M}$, Alonso J, Castilla $\mathrm{M}$, et al. Preoperative testing practice in healthy cataract surgery patients. Results of a survey of ophthalmologists in Barcelona, Spain. Barcelona I-PORT Investigators. Int Ophthalmol 1997;20:31522.
13 Bellan L, Dunn E, Black C. Practices associated with cataract surgery in Canada: results of a national survey. Can $\mathcal{F}$ Ophthalmol 1997;32:315-23.

14 Koch DD. Glare and contrast sensitivity testing in cataract patients. F Cataract Refract Surg 1989;15:158-64.

15 Steinberg EP, Tielsch JM, Schein OD, et al. The VF-14. An index of functional impairment in patients with cataract. Arch Ophthalmol 1994;112:630-8.

16 Steinberg EP, Tielsch JM, Schein OD, et al. National study of cataract surgery outcomes: variation in 4-month postoperative outcomes as reflected in multiple outcome measures. Ophthalmology 1994;101:1131-41. 